\title{
Erratum to: Seed P-enrichment as an effective $P$ supply to wheat
}

\author{
Nobuhito Sekiya $\cdot$ Katsuya Yano
}

Published online: 30 March 2010

(C) Springer Science+Business Media B.V. 2010

Erratum to: Plant Soil (2010) 327:347-354

DOI 10.1007/s11104-009-0058-2

The original article was inadvertently published with an incorrect version of Fig. 3. The horizontal axis unit for Field experiment at Fig. 3 should read ' $\mathrm{g}$ plot ${ }^{-1}$, The correct image is shown here.

Responsible Editor: Richard W. Bell.

The online version of the original article can be found at http:// dx.doi.org/10.1007/s11104-009-0058-2.

N. Sekiya $\cdot$ K. Yano $(\bowtie)$

Laboratory of Crop Science,

Graduate School of Bioagricultural Sciences,

Nagoya University,

Chikusa,

Nagoya 464-8601, Japan

e-mail: kyano@agr.nagoya-u.ac.jp 
Fig. $3 \mathrm{DM}_{\text {shoot }}$ of wheat plants grown from seeds soaked in distilled water (control) and $50 \mathrm{~g} \mathrm{~L}^{-1}$ potassium phosphate solutions (P-enrichment). Plants were grown in pots filled with $400 \mathrm{~g}$ Andisol with 0 , 40,80 , or $240 \mathrm{mg}$ superphosphate pot $^{-1}$, and in field plots with 0,12 , or $36 \mathrm{~g}$ super-phosphate plot ${ }^{-1}$. Each data point represents the mean $\pm \operatorname{SE}(n=6$ for the pot experiment; $n=4$ for the field experiment)

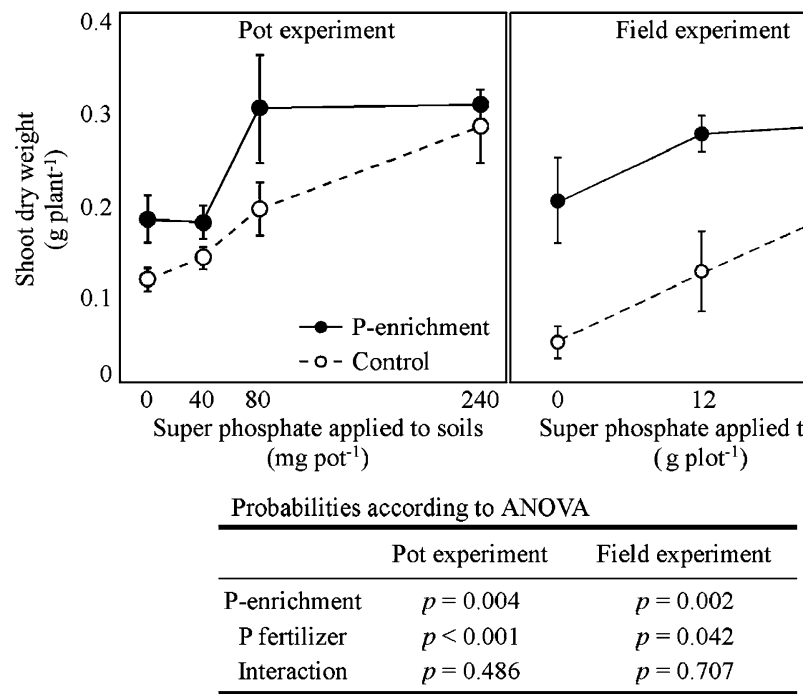

